\title{
Eficiência Elétrica e Distorções Harmônicas com o uso dos Conversores de Frequência nos Sistemas de Bombeamento de Água
}

\section{Electrical Efficiency and Harmonic Distortions with the use of Frequency Inverters in Water Pumping Systems}

\author{
Arnulfo Barroso de Vasconcellos, Dr. Ângelo \\ Bernardo Bridi, Msc.Luciana Oliveira da Silva \\ Lima, Msc.Carlos Henrique Beuter, Eng. \\ Faculdade de Arquitetura Engenharia e Tecnologia \\ Universidade Federal de Mato Grosso - UFMT \\ Cuiabá/MT, Brasil, arnulfo@ufmt.br
}

\author{
Teresa Irene Ribeiro de Carvalho Malheiro, \\ PhD.Instituto Federal de Educação, Ciência e \\ Tecnologia de Mato Grosso - IFMT, \\ Cuiabá/MT, Brasil. malheiro.teresa@gmail.com
}

Enviado: Maio de 2014 Aceito: Junho de 2014 Publicado: Novembro de 2014

Resumo: O uso dos conversores de frequência no acionamento dos motores de indução das bombas centrífugas permite controlar a vazão de descarga proporcionada pelos sistemas de bombeamento através da rotação da bomba. $\mathrm{O}$ método de controle da vazão através da rotação da bomba, em termos de eficiência energética é muito mais eficaz nas reduções do consumo de energia elétrica ativa e da demanda de potência do que o método de controle feito através da regulagem na abertura da válvula ou registro. Porém, o uso do conversor de frequência gera harmônicos de corrente, ao quais podem distorcer a forma de onda senoidal da tensão da rede de fornecimento de energia elétrica. Dentro deste contexto, este artigo visa mostrar vantagens na redução da vazão em sistemas de bombeamento com o uso dos conversores de frequência, mas principalmente mostrar que é preciso atenção especial aos harmônicos gerados com a utilização destes equipamentos.

Palavras-chave: Sistemas de Bombeamento, Controle da vazão, Conversor de Frequência, Distorção Harmônica.

\begin{abstract}
The use of frequency converters in activating the induction of centrifugal pumps motors lets you control the discharge rate provided by the pumping systems by rotating the pump. The method of controlling the flow through the pump rotation, in terms of energy efficiency is much more effective in the reduction of active power consumption and power demand than the control method done by adjusting the valve opening or register. However, the use of the frequency converter generates harmonic current, which may distort the sinusoidal waveform of the voltage of the electricity supply network. Within this context, this article aims to show benefits in reducing the flow in pumping systems with the use of frequency converters, but mainly to show that it takes special attention to the harmonics generated with the use of this equipment.
\end{abstract}

Keywords: Pumping Systems, Flow Control, Frequency Converter, Harmonic Distortion.

\section{INTRODUÇÃO}

Os motores elétricos quando acionados por conversores de frequência tornam-se para o sistema de suprimento de energia elétrica cargas não lineares. Há uma preocupação cada vez maior com as distorções harmônicas causadas pelas cargas não lineares no sistema de suprimento de energia elétrica.

Até algum tempo atrás, a qualidade da energia estava relacionada, sobretudo, com a continuidade dos serviços prestados. A principal preocupação era a não interrupção do fornecimento de energia elétrica, e que a tensão e frequência fossem mantidas dentro de determinados limites considerados aceitáveis. Durante dezenas de anos, a grande maioria dos receptores ligados às redes de energia elétrica era constituída de cargas lineares. Por essa razão, uma vez que as tensões de alimentação eram senoidais, as correntes solicitadas também eram senoidais 
Citação: Vasconcellos A. B., Bridi A. B., Lima L. O. S., Beuter C. H. e Malheiros T. I. R. C., Eficiência Elétrica e Distorções Harmônicas com o Uso dos Conversores de Frequência nos Sistemas de Bombeamento de Água. E\&S - Engineering and Science, (2014), 2:1.

e de mesma frequência, podendo apenas se encontrar defasadas relativamente às tensões. Com os grandes avanços da eletrônica nas últimas décadas, os equipamentos ligados aos sistemas elétricos evoluíram, melhorando na confiabilidade, controlabilidade e na eficiência elétrica permitindo economizar energia. Também, permitindo a execução de tarefas não possíveis anteriormente. Como exemplo de um desses equipamentos, pode-se citar o conversor de frequência. Com a crescente utilização dos conversores de frequência nos acionamentos dos motores elétricos, num futuro não muito distante haverá uma grande solicitação correntes não senoidais. Portanto, se providências não forem tomadas haverá inevitavelmente "poluição" dos sistemas de suprimento de energia elétrica com harmônicos. Altos níveis de distorções harmônicas em uma instalação elétrica podem causar problemas para a própria instalação, para os equipamentos ali instalados, para outros consumidores ligados a mesma rede e para as redes de distribuição das concessionárias.

Normas internacionais, relativas ao consumo de energia elétrica, limitam os níveis de distorção harmônica de tensão com os quais os sistemas elétricos podem operar e impõem que novos equipamentos não introduzam harmônicos de corrente de amplitude superior a determinados valores na rede. No Brasil, a preocupação com a qualidade da energia elétrica vem crescendo cada vez mais, haja visto o empenho do órgão regulador (ANEEL), as concessionárias e os consumidores. A ANEEL através da Resolução Normativa ${ }^{\circ}$ 424/2010 de Dezembro de 2.010, trata da qualidade de energia elétrica no que tange ao serviço e produto em âmbito nacional.

Dentro deste contexto, através de experimentos realizados em laboratório, no presente trabalho buscou-se avaliar eficiência elétrica com a utilização dos conversores de frequência monofásicotrifásicos no controle da vazão, em sistemas de bombeamento. Foi testado os conversores de frequência monofásicos/trifásicos com alimentação monofásica e trifásica, os quais foram denominados de Mon./Tri. e Tri./Tri. Porém, buscou-se, principalmente, verificar a distorção harmônica de corrente causada com a utilização destes equipamentos eletrônicos.

\section{Características do Sistema, da Bancada e da Instrumentação Utilizada nos Testes.}

As experimentações foram realizadas no Laboratório de Eficiência Energética ELETROBRÁS/PROCEL, na Universidade Federal de Mato Grosso (UFMT), em Cuiabá - MT. Foi utilizado um sistema de bombeamento hidráulico com bomba centrífuga, movimentada através de motor elétrico de indução trifásico. Na tubulação de recalque deste sistema, próxima a saída da bomba, encontra-se instalada uma válvula eletromecânica, que permite controlar a vazão de descarga através da abertura da mesma. $\mathrm{O}$ percentual de abertura desta válvula pode ser regulado via computador. Na mesma tubulação encontra-se instalado, também, um medidor eletrônico de vazão para medir a vazão proporcionada pelo sistema.

A altura geométrica elevação do sistema medida em regime permanente de operação foi de 2,43 metros.

A bancada utilizada nos experimentos é amplamente automatizada. O hardware e o software instalados no computador da bancada permitem, via software, dar partida e parar o sistema de bombeamento hidráulico. Também, permitem controlar a vazão proporcionada pelo sistema através da válvula eletromecânica e/ou através da rotação da bomba, escolhendo o tipo de acionamento do motor (via contator ou via conversor de frequência). E ainda, permite selecionar o motor standard ou de alto rendimento para fornecer a potência motriz no eixo da bomba. A Tabela I apresenta as características do motor selecionado para a realização dos experimentos e da bomba do sistema. 
Citação: Vasconcellos A. B., Bridi A. B., Lima L. O. S., Beuter C. H. e Malheiros T. I. R. C., Eficiência Elétrica e Distorções Harmônicas com o Uso dos Conversores de Frequência nos Sistemas de Bombeamento de Água. E\&S - Engineering and Science, (2014), 2:1.

Tabela 1. Características do Motor e da Bomba

\begin{tabular}{cccc}
\hline \multicolumn{2}{c}{ MOTOR STANDARD } & \multicolumn{2}{c}{ BOMBA CENTRÍFUGA } \\
Marca & WEG & Marca & MARK \\
$\mathbf{N}^{\mathbf{0}}$ de Fases & 3 & Modelo & DB \\
Potência & $1,5 \mathrm{CV}$ & $\mathrm{N}^{\circ}$ de Estágios & 1 \\
Frequência & $60 \mathrm{~Hz}$ & Potência & $2 \mathrm{CV}$ \\
Tensão 220/380V & $4,28 \mathrm{~A} / 2,48 \mathrm{~A}$ & Tubo de Sucção & 2 " \\
Rendimento & $78,5 \%$ & Tubo de Recalque & 1.1 ”, \\
Fator de Potência & 0,86 & Rotação Nominal & 3.500 RPM \\
Rotação & $3.370 \mathrm{RPM}$ & Vedação & Selo Mecânico \\
Temp. Máxima & $40{ }^{\circ} \mathrm{C}$ & Roscas & BSP \\
Ip/In & 7,5 & & \\
Fs & 1,15 & & \\
CAT & $\mathrm{N}$ & & \\
Isol: & $\mathrm{B}$ & & \\
Proteção & $\mathrm{IP} 55$ & & \\
\hline
\end{tabular}

$\mathrm{Na}$ Tabela 2 são apresentadas as características dos conversores utilizados.

\section{Tabela 2. Características dos} Conversores

\begin{tabular}{|c|c|c|c|}
\hline \multicolumn{2}{|c|}{$\begin{array}{c}\text { CONV. DE FREQ. } \\
\text { TRI./TRI. }\end{array}$} & \multicolumn{2}{|c|}{$\begin{array}{l}\text { CONV. DE FREQ. } \\
\text { MONO. / TRI. }\end{array}$} \\
\hline Marca & DANFOSS & Marca & SIEMENS \\
\hline Modelo & VLT 2800 & Modelo & $\begin{array}{c}\text { SINAMICS } \\
\text { G110 } \\
\text { CPM } 110 \\
\text { A/N }\end{array}$ \\
\hline $\begin{array}{c}\text { Entrada } \\
1 F\end{array}$ & $\begin{array}{c}1 \mathrm{x} \\
220 / 240 \mathrm{~V} \\
15,2 \mathrm{~A}\end{array}$ & $\begin{array}{c}\text { Entrada } \\
\mathrm{V}\end{array}$ & $\begin{array}{l}200-240 \mathrm{~V} \\
\mathrm{AC} \pm 10 \%\end{array}$ \\
\hline $\begin{array}{c}\text { Entrada } \\
3 F\end{array}$ & $\begin{array}{c}3 \mathrm{x} \\
200 / 240 \mathrm{~V} \\
7,6 \mathrm{~A}\end{array}$ & $\begin{array}{c}\text { Entrada } \\
\text { I }\end{array}$ & $\begin{array}{c}1 \mathrm{~F} \mathrm{AC:} \\
19,7^{\mathrm{a}} \\
47 \mathrm{a} 63 \mathrm{~Hz}\end{array}$ \\
\hline Saída & $\begin{array}{c}6,8 \mathrm{~A}-2,7 \\
\mathrm{kVA}\end{array}$ & Saída V & $\begin{array}{l}\text { 3F AC: } 0 \\
230 \mathrm{~V}\end{array}$ \\
\hline Motor & $1,5 \mathrm{~kW}$ & Saída I & $\begin{array}{c}\text { 3F AC: } 7,8 \\
\text { A } \\
0 \text { a } 650 \mathrm{~Hz}\end{array}$ \\
\hline Proteção & IP 20 & Motor & $1,5 \mathrm{~kW}$ \\
\hline Temp. & $\begin{array}{l}45^{\circ} \mathrm{C} / \\
113^{\circ} \mathrm{F}\end{array}$ & $\begin{array}{l}\text { Temp. } \\
\text { Variacão }\end{array}$ & $\begin{array}{c}-10^{\circ} \mathrm{C} \mathrm{a} \\
40^{\circ} \mathrm{C}\end{array}$ \\
\hline & & Proteção & IP 20 \\
\hline
\end{tabular}

Para a medição das grandezas elétricas foi utilizado o analisador de energia MARH21 do fabricante RMS.

Os esquemas das conexões do analisador de energia, na entrada e na saída dos conversores de frequência, para efetuar as medições das grandezas elétricas, estão sendo mostrados nas Figuras 1 e 2 .
Figura 1. Esquemas de conexão do analisador de energia no conversor de frequência Trifásico/Trifásico.

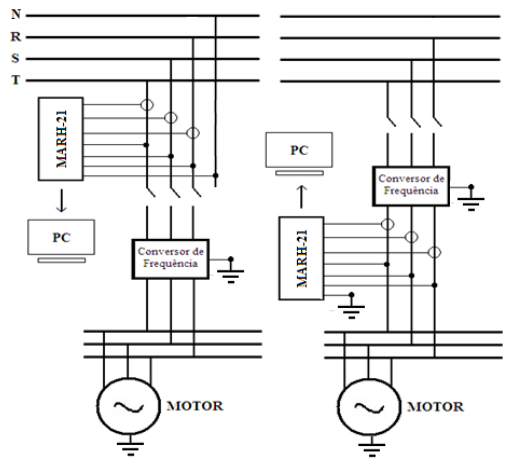

Figura 2. Esquemas de conexão do analisador de energia no conversor de frequência Monofásico/Trifásico
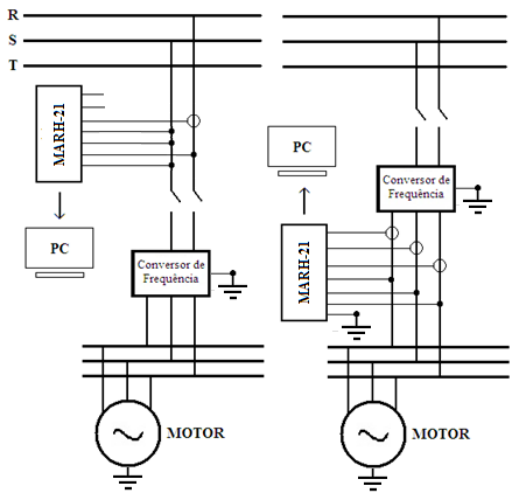

O fluido escoado no sistema foi água limpa a $20^{\circ} \mathrm{C}$. O controle da temperatura da água foi efetuado através do sistema de ar condicionado existente no laboratório. 
Citação: Vasconcellos A. B., Bridi A. B., Lima L. O. S., Beuter C. H. e Malheiros T. I. R. C., Eficiência Elétrica e Distorções Harmônicas com o Uso dos Conversores de Frequência nos Sistemas de Bombeamento de Água. E\&S - Engineering and Science, (2014), 2:1.

A temperatura da água foi medida com o uso de um termômetro comum.

\section{Metodologia de Experimentação $e$ Medição Realizada em Laboratório}

Para analisar a eficiência elétrica do sistema, na utilização do método de controle da vazão através da regulagem na abertura da válvula, foram realizados experimentos

abrindo-se, percentualmente, a válvula eletromecânica computadorizada de $20 \%$ a $100 \%$ de 10 em $10 \%$. O tempo de funcionamento do sistema em cada percentual de abertura da válvula eletromecânica foi de 10 minutos. Dessa forma, foram experimentadas nove (9) graduações de abertura da válvula. O tempo total da experimentação foi de 90 minutos. O acionamento do motor da bomba hidráulica foi efetuado via contator. A velocidade de rotação da bomba medida foi de 3.340 RPM. Após o término da experimentação, foram coletados os dados armazenados na memória de massa do analisador de energia MARH-21 e os dados registrados num arquivo gerado pelo software do computador da bancada do sistema de bombeamento hidráulico utilizado. Foram medidas as vazões proporcionadas pelo sistema, as potências demandadas pelo motor da bomba e os harmônicos existentes no barramento de alimentação.

Para analisar a eficiência elétrica do sistema, na utilização do método de controle da vazão através da rotação da bomba, com o uso do conversor de frequência, foram efetuadas experimentações variando-se a frequência de operação do conversor de 20 a $60 \mathrm{~Hz}$ de $5 \mathrm{em} 5 \mathrm{~Hz}$. Primeiro, foi acionado o motor da bomba através do conversor de frequência com entrada trifásica e saída trifásica (Tri./Tri.) e depois através do conversor de frequência com entrada monofásica e saída trifásica (Mono./Tri.).
O tempo de operação do sistema em cada frequência programada foi de 10 minutos. Dessa forma, foram experimentadas nove (9) rotações da bomba. O tempo total de experimentação com cada conversor de frequência foi de 90 minutos. Após o término das duas experimentações, foram coletados os dados conforme foi descrito na experimentação efetuada anteriormente. Foram medidas as rotações da bomba, as vazões proporcionadas pelo sistema e as potências demandadas pelo motor e os harmônicos gerados nas frequências de operação dos conversores que foram programadas.

Foi desenvolvido um programa computacional no MATLAB para construir os gráficos utilizados.

\section{Potência ativa demandada}

As curvas da potência ativa demandada da rede de alimentação são apresentadas na Figura 3, na utilização do controle da vazão através da válvula e através da rotação da bomba com o uso dos conversores de frequência. Esta Figura mostra que foi obtida uma redução muito maior na demanda de potência ativa, quando a vazão foi reduzida através da rotação da bomba com o uso dos conversores. Pode ser visualizado, também, que nas vazões menores, a potência ativa demandada da rede de alimentação, com a utilização do conversor de frequência trifásico com alimentação monofásica (Mono./Tri.), foi um pouco maior do que aquela demandada com a utilização do conversor de frequência trifásico com alimentação trifásica (Tri./Tri.). Nas vazões maiores, nota-se que ocorreu uma inversão. A potência ativa demandada da rede de alimentação, com a utilização do conversor de frequência com alimentação monofásica, ficou menor do que aquela demandada com a utilização do conversor de frequência com alimentação trifásica. 
Citação: Vasconcellos A. B., Bridi A. B., Lima L. O. S., Beuter C. H. e Malheiros T. I. R. C., Eficiência Elétrica e Distorções Harmônicas com o Uso dos Conversores de Frequência nos Sistemas de Bombeamento de Água. E\&S - Engineering and Science, (2014), 2:1.

A potência ativa demandada da rede de alimentação pelo conversor Mono./Tri. se torna consideravelmente menor nas vazões maiores que $11,5 \mathrm{~m}^{3} / \mathrm{h}$.

Figura 3. Potência ativa demandada da rede de alimentação.

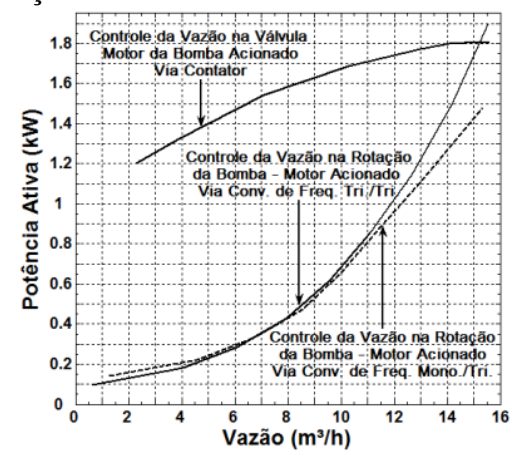

Na Figura 4 são apresentadas as curvas do FP "enxergado" pela rede de energia elétrica, conectada na entrada do sistema de acionamento do motor da bomba utilizado.

Figura 4. Fator de potência (FP) “enxergado" pela rede de alimentação.

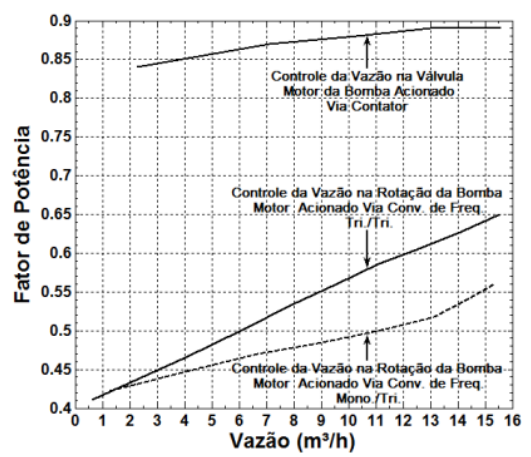

Na Figura 4 pode ser visualizado, que quando o motor da bomba foi acionado via conversor de frequência, o fator de potência apresentado pela carga conversor-motor foi muito mais baixo do que aquele apresentado pela carga motor, quando o acionamento foi efetuado via contator. Pode ser verificado também, na Figura 4, que quando foi utilizado o conversor de frequência trifásico com alimentação monofásica (Mono./Tri.), para as vazões maiores do que $1,75 \mathrm{~m}^{3} / \mathrm{h}$, o fator de potência apresentado pela carga conversor-motor, foi mais baixo do que aquele apresentado quando foi utilizado o conversor de frequência trifásico com alimentação trifásica (Tri./Tri.).

Os experimentos realizados em laboratório mostraram um fator de potência muito baixo com a utilização dos conversores. Portanto, para cargas de potências consideráveis, com motores elétricos de indução acionados via conversores de frequência, o fator de potência deve ser medido e medidas corretivas devem ser aplicadas, caso esteja abaixo do mínimo exigido pela legislação em vigor, que atualmente é 0,92, evitando assim, o pagamento dos excedentes de energia reativa e de demanda reativa.

\section{DISTORÇÃO HARMÔNICA}

Nesta parte será feita uma verificação das formas de onda das tensões e das correntes e dos distúrbios causados pelos harmônicos gerados, com a utilização dos conversores operando em $50 \mathrm{~Hz}$. Serão considerados apenas os harmônicos de ordem ímpar, por serem os característicos gerados por conversores de frequência.

\section{Acionamento do Motor da Bomba Via Contator}

Nesta primeira etapa será feita uma verificação das formas de onda das tensões e das correntes, do conteúdo harmônico das tensões e da distorção harmônica total de tensão nas fases, no barramento de alimentação do motor da bomba. Serão utilizados dados de um experimento realizado no laboratório, com o motor da bomba acionado via contator e a válvula do sistema totalmente aberta. A Figura 5 mostra as formas de onda das tensões ( $\mathrm{Va}, \mathrm{Vb}$, e $\mathrm{Vc}$ ) e das correntes (Ia, Ib e Ic) nas fases A, B e C. 
Citação: Vasconcellos A. B., Bridi A. B., Lima L. O. S., Beuter C. H. e Malheiros T. I. R. C., Eficiência Elétrica e Distorções Harmônicas com o Uso dos Conversores de Frequência nos Sistemas de Bombeamento de Água. E\&S - Engineering and Science, (2014), 2:1.

Figura 5. Formas de onda das tensões e das correntes nas fases $\mathrm{A}, \mathrm{B}$ e $\mathrm{C}$, no barramento conectado ao contator de acionamento.

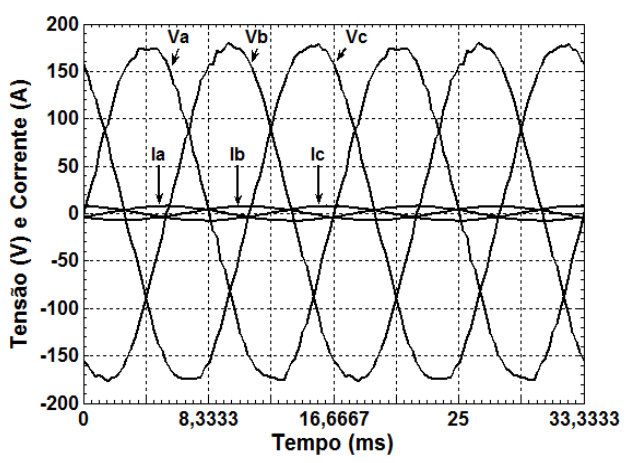

Pode ser verificado na Figura 5, que pelo fato do motor de indução ser uma carga linear, as formas de onda das correntes Ia, Ib e Ic são praticamente senoidais. Pode ser percebido que as tensões no barramento de alimentação do motor da bomba apresentam uma pequena distorção. Esta distorção de tensão é uma distorção já existente no barramento, não foi causada pela carga utilizada neste estudo. A Figura 6 mostra o espectro harmônico da tensão na fase $A$, no barramento de alimentação do motor da bomba. É apresentado apenas o espectro harmônico da fase $\mathrm{A}$, porque para as outras fases o espectro harmônico obtido foi praticamente igual. A distorção harmônica total de tensão na fase $\mathrm{A}$ calculada através do conteúdo harmônico do espectro apresentado foi de 1,4153\%.

Figura 6. Espectro harmônico da tensão na fase A, no barramento conectado ao contator de acionamento.

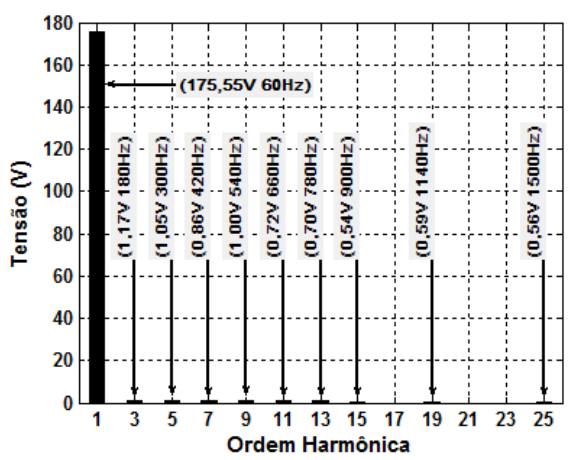

Acionamento do Motor da Bomba Via Conversor de Frequência Trifásico Com Alimentação Trifásica (Tri./Tri.)

Nesta segunda etapa será feita uma verificação das formas de onda das tensões e das correntes, no barramento de alimentação do conversor de frequência Tri./Tri. Foram verificados, também, os harmônicos de corrente gerados e a distorção harmônica total de tensão acrescida no barramento com a utilização deste conversor. Serão utilizados os dados do experimento realizado no laboratório, com o motor da bomba acionado via conversor de frequência Tri./Tri. operando em $50 \mathrm{~Hz}$ (válvula do sistema totalmente aberta).

A Figura 7 mostra as formas de onda das tensões ( $\mathrm{Va}, \mathrm{Vb}$, e $\mathrm{Vc}$ ) e das correntes (Ia, Ib e Ic) nas fases A, B e C, no barramento de alimentação do conversor Tri./Tri. A Figura 8 mostra mais detalhadamente as formas de onda das correntes.

Figura 7. Formas de onda das tensões e das correntes nas fases A, B e C, no barramento de alimentação do conversor de Tri./Tri.

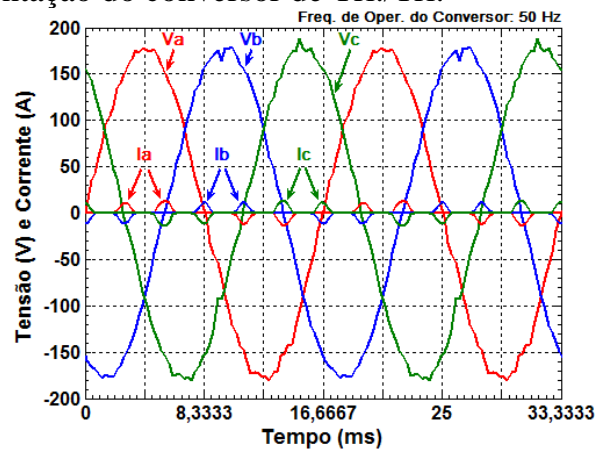

Nas Figuras 7 e 8 pode ser verificado, que pelo fato do acionamento do motor via conversor de frequência transformar o conjunto conversor-motor numa carga não linear, as formas de onda das correntes Ia, Ib e Ic não são senoidais. Pode ser notado também, que os picos de corrente, no retificador trifásico do conversor de frequência, ocorrem quando a tensão de uma das fases é aproximadamente igual a 
Citação: Vasconcellos A. B., Bridi A. B., Lima L. O. S., Beuter C. H. e Malheiros T. I. R. C., Eficiência Elétrica e Distorções Harmônicas com o Uso dos Conversores de Frequência nos Sistemas de Bombeamento de Água. E\&S - Engineering and Science, (2014), 2:1.

zero. Os picos de corrente tendem a correr no instante que a tensão entre as duas fases, responsáveis pelo pico de corrente, é máxima.

Figura 8. Formas de onda das correntes nas fases A, B e C, no barramento de alimentação do conversor de Tri./Tri.

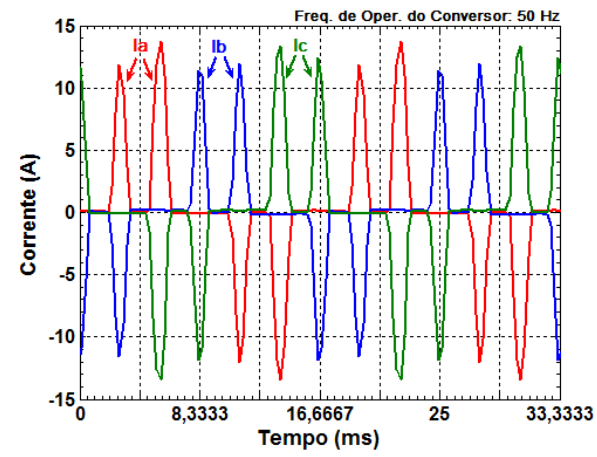

Na Figura 8 nota-se que os dois picos de corrente em cada uma das fases são originados pela participação das ouras duas fases na retificação trifásica de onda completa.

A Figura 9 apresenta o espectro harmônico da corrente na fase A, no barramento de alimentação do conversor Tri./Tri, com o mesmo operando em 50 Hz. Neste espectro, se pode visualizar a presença dos harmônicos de corrente características gerados pelo retificador de seis pulsos $(6 \mathrm{k} \pm 1)$. Pode ser notada, também, a presença significativa dos harmônicos de sequência positiva e negativa alterando $\mathrm{o}$ valor eficaz verdadeiro das correntes das fases $\mathrm{A}, \mathrm{B}$ e C. A distorção harmônica total de corrente na fase A calculada através do conteúdo harmônico do espectro apresentado foi de 125,5777\%. É apresentado apenas o espectro harmônico da fase A, pelo fato da carga ser um motor elétrico de indução trifásico e para as outras fases, os espectros harmônicos serem praticamente iguais.
Figura 9. Espectro harmônico da corrente na fase A, no barramento de alimentação do conversor de frequência Tri./Tri.

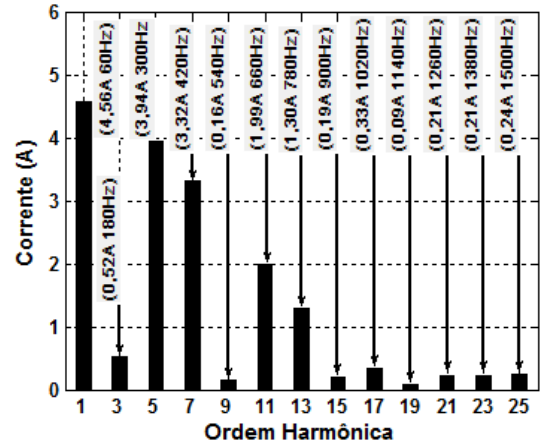

A Figura 10 mostra o espectro harmônico da tensão na fase $\mathrm{A}$, no barramento de alimentação do conversor de frequência Tri./Tri, com o mesmo operando em $50 \mathrm{~Hz}$. É apresentado apenas o espectro harmônico da fase $\mathrm{A}$, porque para as outras fases os espectros harmônicos obtidos foram praticamente iguais. A distorção harmônica total de tensão na fase A calculada através do conteúdo harmônico do espectro apresentado foi de $2,0478 \%$.

Figura 10. Espectro harmônico da tensão na fase A, no barramento de alimentação do conversor Tri./Tri.

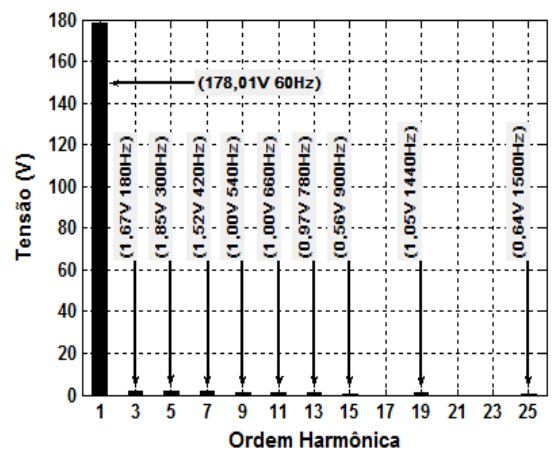

Percebe-se, que com a utilização do conversor de frequência Tri./Tri. operando em $50 \mathrm{~Hz}$, houve um aumento na distorção da tensão do barramento de alimentação de $0,6325 \%$, em relação a distorção que já existia. A distorção na tensão foi pequena, pelo fato da carga (motor de 1,5 CV) ser pequena, em relação a capacidade de carga do 
Citação: Vasconcellos A. B., Bridi A. B., Lima L. O. S., Beuter C. H. e Malheiros T. I. R. C., Eficiência Elétrica e Distorções Harmônicas com o Uso dos Conversores de Frequência nos Sistemas de Bombeamento de Água. E\&S - Engineering and Science, (2014), 2:1.

barramento de alimentação do conversor de frequência.

Acionamento do Motor da Bomba Via Conversor de Frequência Trifásico com Alimentação Monofásica (Mono./Tri.)

Nesta terceira etapa será feita uma verificação da forma de onda da tensão Vab e da corrente Ia na fase A, no barramento de alimentação do conversor de frequência Mono./Tri. Foram verificados, também, os harmônicos de corrente gerados e a distorção harmônica total de tensão acrescida no barramento com a utilização deste conversor. Serão utilizados os dados do experimento realizado no laboratório, com o motor da bomba acionado via conversor de frequência Mono./Tri. operando em $50 \mathrm{~Hz}$ (válvula do sistema totalmente aberta).

$\mathrm{Na}$ Figura 11 é mostra a forma de onda da tensão Vab e da corrente Ia na fase A, no barramento de alimentação do conversor Mono./Tri. A Figura 12 mostra mais detalhadamente a forma de onda da corrente.

Figura 11. Forma de onda da tensão Vab e da corrente Ia na fase $A$, no barramento de alimentação o conversor Mono./Tri.

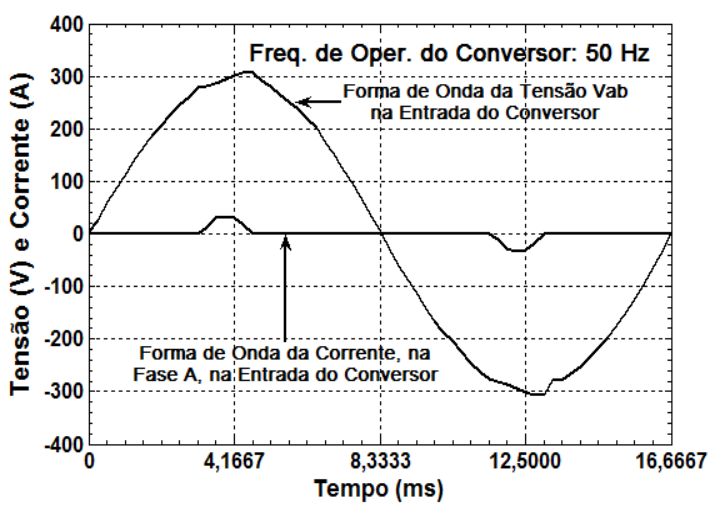

Figura 12. Forma de onda da corrente Ia na fase A, no barramento de alimentação o conversor Mono./Tri

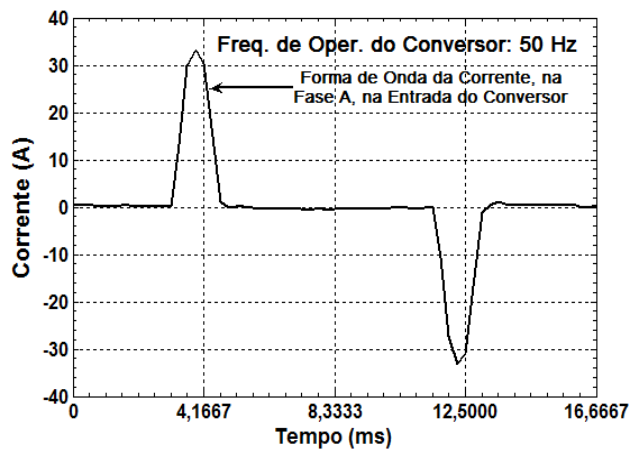

Nas Figuras 11 e 12 pode ser verificado, que pelo fato do acionamento do motor via conversor de frequência transformar o conjunto conversor-motor numa carga não linear, a forma de onda da corrente Ia na fase A não é senoidal. Pode ser notado também, na mesma Figura, que os picos de corrente, no retificador do conversor de frequência com alimentação monofásica, ocorrem com certo adianto em relação aos picos de tensão, indicando ser uma carga mais capacitiva do que o conversor de frequência com alimentação trifásica. No conversor com alimentação monofásica, uma quantidade maior de energia proveniente da fase de alimentação é armazenada no banco de capacitores do filtro do retificador, para eliminar as ondulações da tensão retificada. Pelo fato da tensão Vab se comportar como se fosse uma tensão monofásica, ocorre apenas um pico de corrente em cada semi-ciclo.

A Figura 13 apresenta o espectro harmônico da corrente na fase $\mathrm{A}$, no barramento de alimentação do conversor Mono./Tri, com o mesmo operando em 50 Hz. Neste espectro, se pode visualizar a presença dos harmônicos de corrente características gerados pelo retificador de dois pulsos $(2 \mathrm{k} \pm 1)$. Neste caso, pode ser notado que a os harmônicos de sequência zero fazem parte dos harmônicos característicos gerados pelo retificador de 
Citação: Vasconcellos A. B., Bridi A. B., Lima L. O. S., Beuter C. H. e Malheiros T. I. R. C., Eficiência Elétrica e Distorções Harmônicas com o Uso dos Conversores de Frequência nos Sistemas de Bombeamento de Água. E\&S - Engineering and Science, (2014), 2:1.

dois pulsos (retificador monofásico de onda completa).

Figura 13. Espectro harmônico da corrente na fase A, no barramento de alimentação do conversor Mono./Tri.

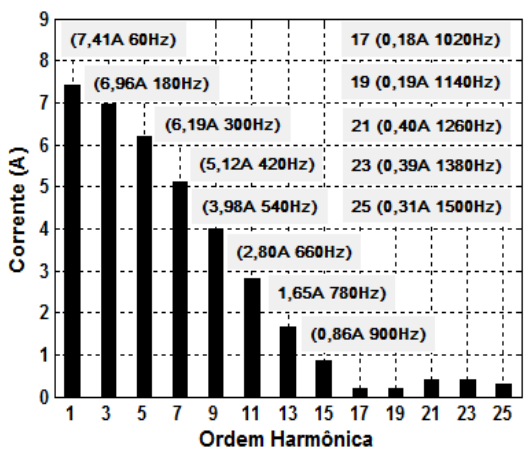

A distorção harmônica total de corrente na fase A calculada através do conteúdo harmônico do espectro apresentado foi de 160,0151\%. A Figura 14 mostra o espectro harmônico de tensão Vab no barramento de alimentação, com o conversor Mono./Tri desligado.

Figura 14. Espectro harmônico da tensão Vab no barramento de Alimentação, com o conversor Mono./Tri. desligado.

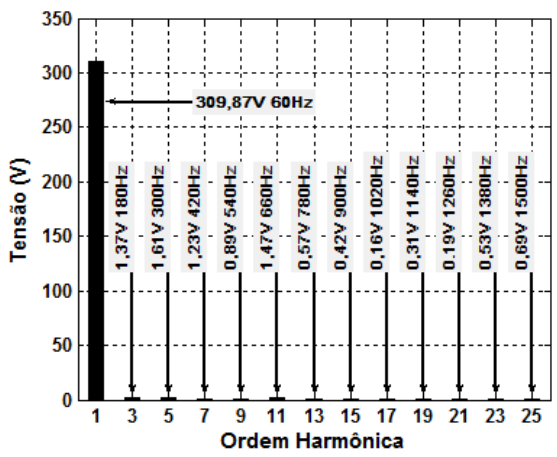

A distorção harmônica total de tensão calculada através do conteúdo harmônico do espectro apresentado foi de $1,0383 \%$.

A Figura 15 mostra o espectro harmônico da tensão Vab, no barramento de alimentação do conversor Mono./Tri, com o mesmo operando em $50 \mathrm{~Hz}$.
Figura 15. Espectro harmônico da tensão Vab, no barramento de alimentação do conversor de frequência Mono./Tri.

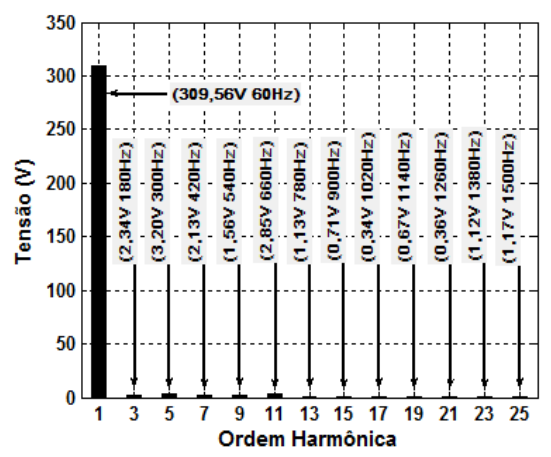

A distorção harmônica total de tensão calculada através do conteúdo harmônico do espectro apresentado foi de foi de $1,9357 \%$. Percebe-se, que com a utilização do conversor de frequência Mono./Tri. operando em $50 \mathrm{~Hz}$, houve um aumento na distorção da tensão Vab no barramento de alimentação de $0,8974 \%$, em relação a distorção que já existia. A distorção na tensão foi pequena, pelo fato da carga (motor de 1,5 CV) ser pequena, em relação a capacidade de carga do barramento de alimentação do conversor de frequência.

\section{Conclusão}

A utilização do conversor de frequência no acionamento do motor de indução de uma bomba centrífuga, para o controle da vazão proporcionada pelo sistema de bombeamento mostrou eficiência elétrica. Porém, os harmônicos de corrente gerados pelos conversores de frequência utilizados nos experimentos, mesmo a carga acionada sendo de baixa potência (motor de 1,5 CV), distorceram "levemente" a tensão no barramento de alimentação. Portanto, os harmônicos gerados com a utilização dos conversores de frequência merecem atenção especial. Medidas mitigadoras devem ser tomadas, a fim de que, os harmônicos de corrente gerados com a utilização destes equipamentos eletrônicos, não causem 
Citação: Vasconcellos A. B., Bridi A. B., Lima L. O. S., Beuter C. H. e Malheiros T. I. R. C., Eficiência Elétrica e Distorções Harmônicas com o Uso dos Conversores de Frequência nos Sistemas de Bombeamento de Água. E\&S - Engineering and Science, (2014), 2:1.

percentuais de distorção harmônica (individual e/ou total) na tensão de alimentação, maiores do que os permitidos pela legislação vigente.

O baixo fator de potência verificado com a utilização dos conversores é outro fator que merece atenção. Para cargas com potências consideráveis com motores acionados via conversores de frequência o fator de potência deve ser medido e medidas corretivas devem ser aplicadas, caso esteja abaixo do mínimo exigido pela legislação em vigor, que atualmente é 0,92 .

\section{Referências}

FRANCHI, CLAITON MORO; Acionamentos Elétricos Disponível gratuitamente no Site: $<$ http://www.baixebr.org/cursos-eapostilas/livros/ebook-acionamentoseletricos/> Acesso em: 10 Jun 2011

FRANCHI, CLAPTON MORO; Inversores de Frequência Teoria e Aplicações. Editora Érica Ltda, $2^{\mathrm{a}}$ edição, São Paulo, 2009.

RODRIGUES, W.; LUVIZOTTO Jr, E.; Inversor de frequência em sistemas de bombeamento; 11p. Disponível em: <http://www.semasa.sp.gov.br/docum entos/assemae/trab_32.pdf $>\quad$ Acesso em 7Abr 2012
CENTRAIS ELÉTRICAS DO

BRASIL S. A.
ELETROBRÁS/PROCEL. Bombas Guia Avançado. Rio de Janeiro, 2004

PORTO, R. M. Hidráulica Básica. São Carlos: EESC-USP, 2006. 540p.

STREETER, Victor Lyle e WYLIE, E. Benjamin; Mecânica dos Fluidos. Editora McGraw-Hill do Brasil Ltda, São Paulo, 1982, 585 p.

PUCRS - Faculdade de Engenharia Departamento de Engenharia Mecânica e Mecatrônica; Bombas.

Disponível em: <http://www.em.pucrs.br/lsfm/alunos/ luc_gab/bombas1.html >. Acesso em 17 Nov 2011

LENCASTRE, A.; Manual de Hidráulica Geral. Editora Edgard Blüncher, São Paulo, 1972, 411p.

UFSC - Universidade Federal de Santa Catarina; Bombas e Estações Elevatórias. Disponível em: <http://www.cca.ufsc.br/ aaap/hidraul ica/bombas/maquinas_operatrizes2.pp t> Acesso em: 20 Nov 2011 